\title{
Nursing ethics and medical ethics
}

\author{
Raanan Gillon Imperial College of Science and Technology, London University
}

Nurses are increasingly concerned with the teaching of ethics within their professional education $(1,2)$. In Britain it is probably true to say that nurses get more teaching than do doctors in critical professional ethics (as distinct from merely being instructed about what one ought to do - traditional professional ethics (3)). There are however (at least) three different motivations for this interest and they need to be clearly differentiated. The first is that nurses are concerned with promoting the best interests of their patients, just as doctors are. Increasingly they are ready and willing to stand up and be counted if they feel that what is being done to a patient by doctors (or any other healthcare workers) is wrong. Critical ethics helps them assess their own position more rigorously, in the light of counterarguments.

The second motivation for an interest in ethics is personal - nurses may from time to time feel that they are being required, in the name of patient care and obedience to higher authority (whether this is medical or nursing), to do things which they themselves believe to be morally wrong. For example they may be required to deceive patients, participate in abortions of which they disapprove, or carry out treatments which they find morally offensive. As moral agents they bitterly resent any such imposition.

The third motivation for their interest in professional ethics is that nurses are increasingly resentful of their ancillary role in medical care (ancilla is the latin for a maidservant, handmaid or female slave, and ancillary is defined as subservient, 'subordinate [to],' or [literally] 'of or pertaining to maidservants'). The more firmly nurses can entrench themselves as an acknowledged profession the more the resented 'ancillary' label and role can be replaced by the concept of nursing as a profession complementary to medicine. Since one of the sociologically approved conditions of 'professionhood' would seem to be possession of a 'professional ethic' (4), a concern with nursing ethics may be seen to benefit this third objective of shedding the ancillary role.

Each of these three objectives can be discerned in Dr Wilson-Barnett's paper in this issue of the journal. Thus she points out the likely benefits to patients and the enhanced moral self-respect of nurses that could be expected if nurses felt permitted honestly to explain to patients whatever the patients had not fully understood (and wished to understand) about their medical problems; if they felt permitted to assess patients' $\vec{N}$ responses to medical management and to relay these back to the doctors even when such responses were adverse; and if they felt permitted to act 'as a friend, guide or advocate' for their patients, even when this involved disagreeing with medical assessments of what was best for them. Her three clinical examples vividly portray situations in which nurses do not feel permitted to act in these ways and some of the problems in patient care and nursing self-respect that can result.

In her first vignette both a student nurse and the $\vec{\varphi}$ other nurses with whom she discusses her worrie of apparently feel unable to discuss a moral dilemm about treatment with the doctors on an extremely bus ward. In the second case both a junior staff nurse on night duty and her ward sister feel they have insufficient authority to discuss a patient's poor prognosis with her, despite her request, because the surgeon and the husband 'felt it unwise' for her to be told. In the third case a nurse suggests to a patient who asks her about alternatives to mastectomy that she discuss these with the doctor before signing the consent form for mastectomy. The nurse is reprimanded both by the doctor and, after his complaint, by the ward sister. In each case it appears that an adequate joint assessment of the moral issues involved, taking into account the perspectives of patient, doctor and nurse, would have improved the patient's care. Similarly, the subservient role of the nurse in each case seems fundamental both to the problem in patient care and to the nurses' moral discomfort.

In addition to issues of patient welfare and nurses' individual moral autonomy Dr Wilson-Barnett's paper also clearly points to the third strand of contemporary nursing concern, notably the desire to shed the handmaiden role and find a niche for themselves as an independent profession, complementary rather than ancillary to medicine. Several of her proposals can be cited in this context. Thus she suggests that nurses should increase their contribution to helping the elderly and chronically disabled or ill 'to manage daily living activities' by increasing and exploiting their 0 understanding of the practical, economic, social, 
sociological and psychological aspects of their problems. She suggests that nurses are 'adopting more responsibility for identifying and planning to resolve or reduce illness and related problems' and that this enterprise 'requires freedom to gain information relevant to the patient's welfare, suggesting ways of dealing with problems and selecting priorities for care with the patient and others caring for him'. She is unhappy about the passivity and fear of responsibility manifested by many nurses and attributes these to 'lowered status, inadequate preparation and (largely) female socialisation'. Medical (and nursing) paternalism is criticised not only in relation to patients but also in relation to nurses: she urges both doctors and nurses to work hard at 'partnership not paternalism' both for the patients' benefit and also 'to promote constructive and satisfying working relationships'.

Here it is worth noting that one of the problems confronting nurses in their bid for independent professional status is that there is nothing necessarily beneficial for patients in such a development. Many of the traditional 'handmaiden' tasks which nurses perform are essential for patients' welfare but do not obviously require professional status. Comforting, chatting with, holding hands with, stroking, feeding, grooming, washing, bathing, cleaning, and making beds for, other people when they are sick, are all traditional nursing tasks, and in many circumstances essential for patient care. But do they require professional skills or professional autonomy to be carried out effectively? Or is there some reason to expect that professionals are likely to reject many such tasks as inappropriate to their status and a waste of their expensive professional time and skills? Even the hallowed guarding and distribution of medicines by nurses in hospital hardly requires professional skills after all we happily allow patients to look after and administer their own drugs when they are out of hospital. It seems more a matter of providing a simple service to those patients who are sick enough to need it.

On the other hand it may be argued that even these simple and ordinary skills need to be exercised in a professional way. Furthermore, and self-evidently modern nursing can require a vast array of additional skills, in effect mirroring the array of new skills acquired by medicine. Thus there are nurses who specialise in psychological counselling (as distinct from merely chatting and comforting), in high-technology intensive care, in complicated chemotherapy, in independent care for the dying, in general practice and nurse-practitioner work, in hospital management, in occupational health, in the traditional nursing specialities such as theatre, midwifery and district nursing, and in a host of other specialisms that involve nurses in the more or less independent exercise of special skills.

Given this wide variety of their functions it is not clear how nurses can come up with a single solution to their dilemmas about occupational status. But from the perspective of their concern with ethics it is fairly clear that at least part of this concern about status is based straightforwardly on occupational self-interest, and while there is nothing wrong with this, it seems important to distinguish it clearly from the other two motives for nursing concern with professional ethics, namely protection of the patient's interests and respect for the moral agency of individual nurses. Whatever the occupational status of nurses, doctors should surely cooperate with nurses so as to enable them to participate in the moral decisions which affect the patients they nurse and/or those which independently have moral implications for the nurses themselves. Such cooperation can be achieved, for example, by means of the regular staff meetings designed to discuss such issues which many hospital and primary care units already hold.

Professional ethics seem less obviously relevant to the issue of occupational status except in so far as changes in nursing status can be expected either to enhance or reduce the quality of patient care, and this seems likely to vary according to the type of nursing care required in different circumstances. Certainly the issue of occupational status does not seem to require or justify a professional ethic for nurses fundamentally different from medical ethics; it would on the contrary seem far preferable if nurses and doctors and indeed all the health-care professions could accept a common ethic, perhaps based on the four prima facie moral principles described and defended by Beauchamp and Childress (5), namely respect for autonomy, beneficence, non-maleficence and justice.

As indicated above, part of some nurses' contemporary reluctance to accept codes of medical ethics has been based on their rejection of subservience to medicine. As medical ancillaries they have traditionally been expected simply to do what the doctor ordered. If, for example, a doctor decided that it was in the patient's best interests that his or her diagnosis was withheld, so be it, the nurses's duty was to withhold the information. (There is a rather bitter nursing joke about a sick patient who died and found himself in bed in heaven. Uncertain where he was he asked an angelic nurse, as she changed his heavenly sheets, 'Nurse, where am I - did I die?' - to which the nurse replied, 'I'm sure it would be best if you discussed it all with the doctor'). But medical ethics properly understood requires no such subservience. Under its principles colleagues as well as patients are owed respect. Given such respect there seems no reason why nurses, doctors and other health-care workers should not co-operate in their common enterprise of optimising patient care, instead of going their separate ethical ways. Such co-operation, as $\mathrm{Dr}$ Wilson-Barnett stresses, will require tact on both sides and this tact should surely include recognition that doctors no less than nurses and other health-care workers also see themselves as their patients' friends, guides and advocates; and that doctors no less than

(continued on page 122) 
(5) Walters L. Confidentiality. In: Beauchamp T L, Walters L, eds. Contemporary issues in bioethics. Encino/ Belmont: Dickenson, 1978: 169-175.

(6) Handbook of medical ethics. London: British Medical Association 1981.

(7) Anonymous. Medical confidentiality [editorial]. Fournal of medical ethics 1984; 10: 3-4.

(8) Carli T. Confidentiality and privileged communication: a psychiatrist's perspective. In: Basson $M \mathrm{D}$, ed. Ethics, humanism, and medicine. New York: Liss, 1980: 245251.

(9) Rawls J. A theory of justice. Cambridge, Mass: Belknap Press, 1971: 342-350.

(10) Melden A I. Rights and persons. Oxford: Blackwell, 1977: $47-48$.

(11) Morris H. The status of rights. Ethics 1981; 92: 40-56.

(12) Veatch R M. A theory of medical ethics. New York: Basic Books, 1981: 184-189.
(13) Levenbook B B. Harming someone after his death. Ethics 1984; 94: 407-419.

(14) Veatch R M. Case studies in medical ethics. Cambridge/ London: Harvard University Press, 1977: 131-135.

(15) Culver C M, Gert B. Philosophy in medicine. New York: Oxford, 1983: 26-28.

(16) Siegler M. Medical consultations in the context of the physician-patient relationship. In: Agich G J, ed. Responsibility in health care. Dordrecht: Reidel, 1982: 141-162.

(17) Havard J. Medical confidence. Fournal of medical ethics 1985; 11: 8-11.

(18) Robins R S, Rothschild H. Hidden health disabilities and the presidency: medical management and political consideration. Perspectives in biology and medicine 1981; 24: 240-253.

(See also Case conference page 151.)

(continued from page 116)

nurses are concerned with their patients as people and not merely as cases of disease or potential disease. The moral objectives of nurses and doctors are surely the same - only the perspectives are different.

The obvious danger if nurses fail to keep distinct the three components of their developing concern with professional ethics is that patients will suffer as, in the name of nursing ethics, they are used as shuttlecocks in an increasingly bitter interprofessional battle about the occupational status of nursing $(6,7)$. That is an outcome which all who are concerned with the welfare of patients would surely wish to avoid.

\section{References}

(1) Thompson I E, Melia K M, Boyd K M. Nursing ethics. Edinburgh: Churchill-Livingston, 1983; vi.
(2) McTaggart A R, et al. Nurses have dilemmas too [correspondence]. British medical journal 1983; 286: 1214.

(3) For a brief differentiation between these two concepts of professional ethics see: Anonymous. Two concepts of medical ethics [editorial]. Fournal of medical ethics 1985; 11: 3 .

(4) See for example: Pernick M S. Medical professionalism. In: Reich W T ed. Encyclopedia of bioethics. London: Collier Macmillan, 1978; 1028-1033.

(5) Beauchamp T L, Childress J F. Principles of biomedical ethics (2nd ed). Oxford: Oxford University Press, 1983.

(6) Anonymous. Changing relations between doctors and nurses: CCHMS critical of RCN's discussion documents. British medical journal 1982; 285: 1130-1132.

(7) Mitchell J R A. Is nursing any business of doctors? A simple guide to the 'nursing process' (with reply by Rowden R). British medical journal 1984; 288: 216-221. 